\title{
Perceptions of primary health care service users regarding dental team practices in Brazil
}

\author{
Alexandre Baumgarten ${ }^{1}$, Rochelle Santos Da Veiga ${ }^{2}$, Patricia Tavora Bulgarelli ${ }^{1}$, Vitor Motta Diesel $^{2}$ and \\ Alexandre Favero Bulgarelli ${ }^{3}$ \\ ${ }^{1}$ Research Associate, Faculty of Dentistry, Federal University of Rio Grande do Sul, Porto Alegre, Brazil \\ ${ }^{2}$ Graduate Student, Faculty of Dentistry, Federal University of Rio Grande do Sul, Porto Alegre, Brazil \\ ${ }^{3}$ Professor of Primary Dental Care, Collective Health Postgraduate Programme, Federal University of Rio Grande do \\ Sul, Porto Alegre, Brazil
}

\begin{abstract}
Background: The Unified Health System (SUS) is the Brazilian set of public health services that offers global access to health care and disease treatments for all citizens. These services have been evaluated by means of a national survey assessing the users' perceptions. Aim: To explore and characterize the SUS users' perceptions regarding primary dental team practices in the five Brazilian geographical regions. Methods: Descriptive study. The sample consisted of 37262 subjects. Data were collected by means of the Ministry of Health survey, conducted between 2012 and 2014. Variables used in the present study are associated with SUS users' perspectives of satisfaction, access, and use of services. The study utilized bivariate data analysis, and dichotomous variables were derived for analysis following 95\% reliability. Findings: This study observed similarities and proportionality of perceptions in the Brazilian territory. In most macro-regions, dental teams did not develop an active search for dental treatment absentees. However, the SUS users reported very good and good perceptions, which were homogeneously distributed across five Brazilian regions, thereby showing an overall positive perception of primary dental treatment.
\end{abstract}

Key words: primary health care; public health services; Unified Health System (SUS)

Received 23 March 2017; revised 23 August 2017; accepted 25 August 2017;

first published online 9 October 2017

\section{Introduction}

The Unified Health System (acronym in Portuguese is SUS) is the set of Brazilian public health services that offers universal access to all levels of health care and treatment to support Brazilian health needs. The SUS offers free services ranging from health promotion and primary care to specialized treatments by means of integrating services with a perspective of comprehensive care for its users. This integration is accomplished by offering health services of all complexities within a health care network. In other words, the SUS has many integrated services, including hospitals, primary health centres, centres of urgency and

Correspondence to: Alexandre Favero Bulgarelli, R. Ramiro Barcelos, 2492 - Santa Cecilia, Porto Alegre, RS 90035-004, Brazil. Email: alexandre.bulgarelli@ufrgs.br emergency, laboratories, specialized clinics, and dental clinics/centres.

To coordinate this health services network, the SUS uses Primary Health Care (PHC) as the axis for the organization of health personnel practices and conduct, the adequacy of resources and services, health care delivery and access to different services, all of which involve different levels of complexity (Brazil, 2006; 2012). Furthermore, the SUS has a fundamental role within the Brazilian government because the SUS was constructed by means of social and health policies on behalf of the entire Brazilian population. In this process, the Ministry of Health conducts constant assessments to evaluate the actions and services of the SUS. All the assessments and surveys are important for the development of public health programmes and health care models in Brazil and Latin America (Brazil, 2006; 2012). Among all the health care 
models that exist in the SUS, the primary dental treatment and oral health promotion services are delivered through the Family Health Strategy (FHS). This health care model is a program of the National Dental Health Policy (NDHP) and the National Primary Care Policy (NPCP) (Cordòn, 1997; Brazil, 2006; 2007).

The entire framework underpinning the provision of qualified services in the SUS emerges from a concept that is structured in certain aspects, such as health promotion, primary health treatment, and specialized health treatment. Therefore, the Brazilian $\mathrm{PHC}$ is responsible for connecting with various health practices inside the services to provide qualified oral health care and dental treatments (Brazil, 2006; 2012). Per these assumptions, the FHS is the most widely distributed health care model and reaches almost all Brazilian territories. The PHC services in the SUS are important to the citizens' health because the services offer primary care treatment in all Brazilian territory (Mendes, 2002). The literature shows that primary health practices are becoming integrated into the culture and routines of the health care organizations (Whitelaw et al., 2016). Moreover, in Brazil, the PHC represents the possibility to construct better health care models to create a strong link between the service and the user with respect to commitment and mutual responsibilities (Mendes, 2001; 2002; Starfield, 2002).

Coordination of care, commitment linkages, and mutual responsibilities are concepts that should be assessed in public health services by means of periodic surveys. The development of assessment studies makes professionals visualize their potentialities, failures, and weaknesses. This provides resources for qualifying care and continuity of treatment, offering access to other levels of care, such as specialized treatments (Moimaz et al., 2010). Furthermore, users' perception is essential to assess the quality of oral health services and dental treatment. It is the service users, by means of their point of view, who can point out important situations.

The question of the present study regarding services being offered is as follows: how do users of the SUS perceive issues regarding dental team practices in the PHC services? This question can be studied by means of a nationwide assessment of the users of the PHC service. The study, therefore, aimed to explore and analyse SUS users' perceptions regarding the development of active searches for absentees, treatment by the same dentist and information received about self-care in oral health in the five Brazilian geographical macro-regions.

\section{Methods}

This is a nationwide cross-sectional exploratory study of public health services. For this study, 37262 users of primary dental care and treatments offered by the SUS were assessed. Data were collected by means of the second cycle of the National Program for Access and Quality Improvement (acronym in Portuguese is PMAQ), which was developed by the Ministry of Health (Brazil, 2007). For data collection, evaluators were selected and trained uniformly according to a field manual prepared by the PMAQ. The questionnaire used for data collection was packaged into a specific Android-based application, which was installed onto tablet computers for data input. Data were sent through the internet and analysed by the Ministry of Health to ensure their quality.

The survey was conducted between 2012 and 2014 in all five geographical Brazilian macro-regions (north, northeast, midwest, south, and southeast). All participants were interviewed in the waiting room at the health centre facility. The exploratory variables used in the present study were 'Being assisted by the same dentist' and 'Information received about self-care in oral health'. These variables were associated with positive perceptions of the received dental care and treatment. The descriptive analysis was developed to associate professional team practices and quality of received treatment with the Brazilian macro-regions. The studied variables were derived from questions on the PMAQ questionnaire (Brazil, 2007).

Among the questions from the PMAQ questionnaire, the following were used in the present study: 'Do the oral health care guidelines/ orientation given to you by the dental team in the centre fulfil your needs for self-care? (Yes or no)'; 'Does the same dentist assists you during the treatment? (Always, Most of the time, Almost never, or Never)'; 'When you interrupt treatment or do not come to the dental office for any reason, does the dental team ask what occurred regarding your absence? (Yes or no)'; 'In your opinion, how was the treatment that you received from the dental team/staff? (Very good, Good, Fair, Bad, 
Very bad)'. According to the statistical power of the sample, the variable 'Assisted by the same dentist' was dichotomized in its answer with Always and Most of the time $=$ Yes, and Almost never or Never $=$ No. There was a non-response and refusal rate of $7 \%$. Bivariate and associative data analyses were performed. The $\chi^{2}$ and one-way ANOVA tests were used to check for associations between the independent variables and the provision of positive perception. Data were analysed using SPSS v21 software (SPSS Inc., Chicago, IL, USA). To associate the outcome of positive perception with 'Being assisted by the same dentist' and information received for self-care in oral health', dichotomous variables were derived for analysis following $95 \%$ reliability.

The survey was conducted with minimal risks to humans. The study was approved by the Federal University of Rio Grande do Sul Research Ethics Committee under protocol number 21904/2011.

\section{Results}

The study sample was characterized by a higher prevalence of women (79.6\%), a mean age of 45.3 years, an unemployed percentage of $66.9 \%$, and a $68.2 \%$ rate of receiving government family grants. The clear majority of the sample could read and write $(98.0 \%)$. There are similarities and proportionalities in all Brazilian macro-regions regarding SUS users' perceptions of the dental team practices in the PHC services (Tables 1, 2 and 3). In most macro-regions, dental teams do not actively search for dental treatment absentees. The southeast region had a higher prevalence of this $(18.1 \%)$, as well as a higher percentage on the 'Information received by the dental team about self-care in oral health' variable (78.4\%) (Tables 1, 2 and 3).

In general, the respondents reported with very good and good perceptions that were homogeneously distributed among the five Brazilian macro-regions (Table 4). The present study showed a good perception regarding primary dental team practices. Furthermore, important subjects, such as 'being assisted by the same dentist' and 'receive information about self-care in oral health from the dental team', were associated with a positive perception of practices. The Midwest region had the higher prevalence of 'being treated and assisted by the same dentist' (77.5\%) (Table 5).

\section{Discussion}

This unprecedented nationwide study presents important data regarding primary dental assistance

Table 1 Information received by the professional team about self-care in oral health. SUS users' perceptions. Brazil, 2016.

\begin{tabular}{|c|c|c|c|c|c|c|}
\hline Macro-regions & Always & Most of time & Almost never & Never & Not answered & Total \\
\hline North & $1659(67.6 \%)$ & $456(18.6 \%)$ & $130(5.3 \%)$ & $178(7.2 \%)$ & $29(1.1 \%)$ & 2452 \\
\hline Northeast & $11820(74.8 \%)$ & $2353(14.9 \%)$ & $564(3.6 \%)$ & $957(6 \%)$ & $96(0.6 \%)$ & 15790 \\
\hline Midwest & 1752 (74\%) & $372(15.7 \%)$ & $93(3.9 \%)$ & $126(5.3 \%)$ & $22(0.9 \%)$ & 2365 \\
\hline South & $4679(77.6 \%)$ & $855(14.2 \%)$ & $180(3 \%)$ & $235(3.9 \%)$ & $79(1.3 \%)$ & 6028 \\
\hline Southeast & $8328(78.4 \%)$ & $1400(13.2 \%)$ & $323(3 \%)$ & $456(4.3 \%)$ & $120(1.2 \%)$ & 10627 \\
\hline
\end{tabular}

Table 2 Treated and assisted by the same dentist. SUS users' perceptions. Brazil, 2016.

\begin{tabular}{lcclrrr}
\hline Macro-regions & Always & Most of time & Almost never & Never & Not answered & Total \\
\hline North & $1542(62.8 \%)$ & $558(22.7 \%)$ & $236(9.62)$ & $69(2.8 \%)$ & $47(1.9 \%)$ & 2452 \\
Northeast & $11675(74 \%)$ & $2799(17.7 \%)$ & $898(5.7 \%)$ & $207(1.3 \%)$ & $211(0.74 \%)$ & 15790 \\
Midwest & $1834(77.5 \%)$ & $360(15.2 \%)$ & $103(4.3 \%)$ & $26(1.1 \%)$ & $42(1.8 \%)$ & 2365 \\
South & $4258(67.8 \%)$ & $1211(20 \%)$ & $300(4.9 \%)$ & $114(1.9 \%)$ & $145(2.4 \%)$ & 6028 \\
Southeast & $8031(75.5 \%)$ & $1652(15.3 \%)$ & $486(4.5 \%)$ & $170(1.6 \%)$ & $288(2.7 \%)$ & 10627 \\
\hline
\end{tabular}


Table 3 Dental team developing active searches for dental treatment absentees. SUS users' perceptions. Brazil, 2016.

\begin{tabular}{lrrrrrrr}
\hline \multicolumn{1}{c}{ Yes } & Sometimes & \multicolumn{1}{l}{ No } & $\begin{array}{l}\text { User never missed } \\
\text { appointment }\end{array}$ & $\begin{array}{l}\text { User did } \\
\text { not know }\end{array}$ & Total \\
\hline North & $279(11.3 \%)$ & $133(5.4 \%)$ & $772(31.4 \%)$ & $1232(50.2 \%)$ & $36(1.7 \%)$ & $2452(100 \%)$ & $<0.00 *$ \\
Northeast & $2027(12.8 \%)$ & $865(5.5 \%)$ & $4205(26.6 \%)$ & $8502(53.8 \%)$ & $191(1.3 \%)$ & $15790(100 \%)$ & $<0.00 *$ \\
Midwest & $337(14.3 \%)$ & $108(4.5 \%)$ & $605(25.4 \%)$ & $1268(53.4 \%)$ & $47(2.4 \%)$ & $2365(100 \%)$ & $<0.00 *$ \\
South & $827(13.7 \%)$ & $239(4.0 \%)$ & $1468(24.3 \%)$ & $3386(56.2 \%)$ & $108(1.8 \%)$ & $6028(100 \%)$ & $<0.00 *$ \\
Southeast & $1927(18.1 \%)$ & $422(4.0 \%)$ & $2196(20.6 \%)$ & $5901(55.5 \%)$ & $181(1.8 \%)$ & $10627(100 \%)$ & $<0.00 *$ \\
\hline
\end{tabular}

*Pearson $\chi^{2}$ test

Table 4 SUS users' perceptions regarding quality of care received by dental team professionals. Brazil, 2016.

\begin{tabular}{|c|c|c|c|c|c|c|}
\hline & Very good/good & Regular & Bad/too bad & Not answered & Total & $P$-value \\
\hline North & $2013(82.1 \%)$ & $363(14.8 \%)$ & $64(2.6 \%)$ & $12(0.5 \%)$ & $2452(100 \%)$ & $<0.00^{*}$ \\
\hline Northeast & $13621(86.2 \%)$ & $1842(11.6 \%)$ & $262(1.6 \%)$ & $65(0.6 \%)$ & $15790(100 \%)$ & $<0.00^{*}$ \\
\hline Midwest & $2082(88.0 \%)$ & $217(9.2 \%)$ & $54(2.3 \%)$ & $12(0.5 \%)$ & $2365(100 \%)$ & $<0.00^{*}$ \\
\hline South & $5479(90.1 \%)$ & $447(7.4 \%)$ & $77(1.2 \%)$ & $25(1.3 \%)$ & $6028(100 \%)$ & $<0.00^{*}$ \\
\hline Southeast & $9543(89.6 \%)$ & $836(7.8 \%)$ & $190(1.7 \%)$ & $58(0.9 \%)$ & $10627(100 \%)$ & $<0.00^{*}$ \\
\hline
\end{tabular}

*Pearson $\chi^{2}$ test.

Table 5 Variable associated with positive perceptions to the dental treatment. SUS users' perceptions. Brazil, 2016.

\begin{tabular}{lllllllll}
\hline & \multicolumn{6}{l}{ Very good and good perception regarding dental team practices } \\
\cline { 2 - 7 } & North & Northeast & Midwest & South & Southeast & Total & $P$-value \\
\hline $\begin{array}{l}\text { Assisted by the } \\
\text { same dentist }\end{array}$ & $1542(5.6 \%)$ & $11675(42.7 \%)$ & $1834(6.7 \%)$ & $4258(15.6 \%)$ & $8031(29.4 \%)$ & $27340(100 \%)$ & $0.001 *$ \\
$\begin{array}{l}\text { Orientation } \\
\text { received about self- } \\
\text { care in oral health }\end{array}$ & $1659(5.8 \%)$ & $11820(41.8 \%)$ & $1752(6.2 \%)$ & $4679(16.5 \%)$ & $8328(29.7 \%)$ & $28238(100 \%)$ & $0.002 *$ \\
\hline
\end{tabular}

*One-way ANOVA test.

and oral health care in a public health system. It is an original study to comprehend SUS users' perspectives regarding oral health care. The present study shows results with similar social and demographic sample characteristics as previous studies (Moimaz et al., 2010; Silva et al., 2011; Dos Santos et al., 2015). Because the research subjects were literate, they may have had the ability to process and understand oral health information. Oral health literacy is a multidimensional construct that is associated with dental beliefs and attitudes. Subjects with higher education levels have significantly better oral health literacy (Khan et al., 2014; Macek et al., 2017).
Brazilian public policies regarding oral health care and primary dental treatment were fundamental in reaching the current homogeneous perception in each Brazilian region. This result explains the fact that primary dental assistance and oral health promotion are well done nationwide in Brazilian public services (Starfield, 2002; Brazil, 2006; 2007; Clementino et al., 2015).

The NPCP covers treatment in all primary care instances connecting the user with all dental and medical specialities. The actions developed by means of this policy are responsible for the positive SUS users' perspective regarding some principles of the Brazilian public dental service. 
One principle concerns the professional linkage and respect of the users. According to the NPCP, the professional linkage is associated with the information that the user receives from the medical and dental team. The information/guidance should be accessible with respect to language, culture, and the user's social space (Brazil, 2007).

In the present study, the users' perspectives regarding the linkage between services and users were observed in two circumstances. First, when users receive the professional orientation/ guidance for self-care of their oral health. Second, when they are treated by the same dentist during their treatment. Users feel connected and linked to their personal dentist and dental team, and they feel respected, secure, and welcomed. The professional connection between dentists and service users are subjects of Brazilian public politics (Brazil, 2006; 2007).

All the positive perceptions highlighted in this study are constructed in each professional encounter by means of therapeutically negotiatedconstructions between both subjects (Barros and Botazzo, 2011; Schneider and Botazzo, 2015). Another aspect related to the professional linkage between the user and the public health service is the reorientation of the health care model to the primary health care principles (Starfield, 2002). The present study has the perspective that working in PHC principles means that the space between the service and the user is structured to allow encounters and exchanges of experiences regarding common values and expectations (Nicoli et al., 2016).

In Brazil, the narrow relation between the health service and the community needs improvement. However, SUS users' perceptions are positive regarding primary care treatment when compared with users' perception regarding specialized health services (Rocha and Goes, 2008; Van Stralen et al., 2008; Moimaz et al., 2010). This suggests that PHC services are better accessed than specialized services.

Health professionals from SUS construct a stronger linkage with users than professionals from traditional health care clinics (Van Stralen et al., 2008). It is observed, by means of the SUS users' perceptions, that the primary dental treatment within the family health care model is more accessed than dental treatment in traditional health care clinics (Chaves et al., 2012). This result may explain the presence of a positive homogeneous perception of primary dental services in Brazil.
As a limitation of this study, there was no comparison between the perceptions of different health care models. However, the average perception of the primary dental care model was good, which reflects the potential of the Brazilian public health service with regard to oral health care (Tables 3, 4 and 5). There is professional team orientation, which can reflect adequate treatment plans and good therapeutic construction. These aspects were positively associated with the quality of health treatment in all Brazilian regions (Table 5).

The south and southeast regions had higher concentrations of positive perception for variables such as 'being treated and assisted by the same dentist' and 'receive good information for self-care in oral health' (Tables 1 and 2). The south and southeast Brazilian regions had better social and economic indicators and a lower number of socially vulnerable people. Clarifying doubts was a fundamental aspect of good care in oral health in SUS (Martins et al., 2014). These results possibly explain the positive perception of the SUS by users. However, actions regarding access to primary health care have started in the northernmost regions of the country instead of the southernmost regions.

Even with an average positive perception of PHC actions, the active search for absentees was not frequently developed by the dental teams. This could be a failure of the dental team service. Actively searching for dental treatment absentees is an assumption of the primary health care model that results in a strong linkage between the service and user. This is a finding of the present study which is a principle of PHC (Brazil, 2006). There were no positive perceptions of active searching for absentees in any Brazilian region. The suggestion is that this PHC action should be improved in the SUS. The southeast region performed the lowest number of active searches for dental treatment absentees, while the northeast region presents a lower prevalence of users who were absent from dental treatment (Table 3). These are important facts to be observed by the Ministry of Health.

There are several reasons for the absenteeism, including needing to schedule appointments outside working hours, users' lack of interest in dental treatment and dissatisfaction with the professional who attends (Gonçalves et al., 2015). Absenteeism requires an active search for the absentees, and the effectiveness of the actions of the FHC model are relevant in the context of these searches, especially 
in endodontics consultations (Bulgareli et al., 2013; 2014; Protasio et al., 2014). Thus, it is important to invest in and support this model of health care to improve the actions of active searches. In the northeast region, it is possible to observe that there still is no user access to secondary levels of attention (Protasio et al., 2014). Nevertheless, access to PHC care is positively perceived in Brazil. The problem possibly exists with other models of health care (Protasio et al., 2014; Sobrinho et al., 2015).

In general, when SUS users were asked about practices of the dental team from PHC services, the perspective that the development of such practices was good and very good was homogeneous. There were no statistically significant differences among the Brazilian macro-regions (Table 4). This perception shows that, in at least one respect, the dental assistance and care in PHC is satisfactory to SUS users. In this context, it should be emphasized that the PHC is a set of public services that leads people to take care of their health (Nicoli et al., 2016). This approach leads to comprehensive care, within linkages and professional information, resulting in overall positive perceptions of the SUS.

\section{Summary and final considerations}

The present study presents data showing that there is good attention to oral health in the primary care that is reflected in the positive perceptions of users. Often, having access to dental primary care and treatment appears to result in a positive perception. The fact that the SUS users receive information from the dentist who attends to them consistently leads to a positive perception of the received treatment. This positive perception is associated with the presupposition of a linkage between services and users. Primary dental services may receive the same governors' investment nationwide, which was reflected in the homogeneous positive perception across Brazil.

Since this is a national study where the subjects freely participated, such data cannot affirm that Oral Health in PHC in the SUS is satisfactory in all Brazilian territories. Work still needs to be done for effective oral health care in SUS. However, users noted a certain quality in the received dental care.

Primary Health Care Research \& Development 2018; 19: 309-315

\section{Acknowledgements}

We are pleased to thank the Brazilian Ministry of Health regarding the financial support to the development of the National Program for Access and Quality Improvement.

\section{References}

Barros, R.S. and Botazzo, C. 2011: Subjectivity and clinical practice in primary care: narratives, life histories and social reality. [Subjetividade e clínica na atenção básica: narrativas, histórias de vida e realidade social]. Ciência e Saúde Coletiva 16, 4337-348.

Bulgareli, J.V., Faria, E.T., Ambrosano, G.M.B., Vazquez, F.L., Cortellazzi, K.L., Meneghim, M.C., Mialhe, F.L. and Pereira, A.C. 2013: Information from secondary care in dentistry for evaluation of models of health care. Revista de Odontologia da UNESP 42, 229-36.

Bulgareli, J.V., Cortellazzi, K.L., Ambrosano, G.M.B., Meneghim, M.C., Faria, E.T., Mialhe, F.L. and Pereira, A.C. 2014: Resolubility in oral health for primary care as an instrument for the evaluation of health systems. Ciência \& Saúde Coletiva 19, 383-91.

Brazil. Ministry of Health 2006. National policy of primary care. [Política nacional de Saúde Bucal]. Brasília. Ministério da Saúde.

Brazil. Ministry of Health 2007. Brazil's national oral health policy: record of a historic achievement [A política nacional de saúde bucal do Brazil: registro de uma conquista histórica]. Brasília: Organização Pan-Americana da Saúde.

Brazil. Ministry of Health 2012. Programme of quality to access in primary care. [Programa Nacional de qualidade do acesso]. Brasília: Ministério da Saúde.

Chaves, S.C.L., Soares, F.F., Rossi, T.R.A., Cangussu, M.C.T., Figueiredo, A.C.L., Cruz, D.N. and Cury, P.R. 2012: Characteristics of the access and utilization of public dental services in medium-sized cities. Ciência \& Saúde Coletiva 17, 3115-124.

Clementino, F.S., Gomes, L.G., Vianna, R.P.T., Marcolino, E.C., Araújo, J.P. and Chaves, T.V. 2015: Reception in basic care: analysis based on the external evaluation of the program to improve access to and quality of basic care. [Acolhimento na atenção básica: análise a partir da avaliação externa do programa de melhoria do acesso e da qualidade da atenção básica]. Revista Saúde \& Ciência Online 4, 62-80.

Cordòn, J. 1997: The construction of an agenda for community oral health [A construção de uma agenda para a saúde bucal coletiva]. Cad Saúde Pública 13, 557-63.

Dos Santos, M.L.M.F., da Cruz, S.S., Gomes-Filho, I.S., de Santana, P.S.J., Godoy-Figueiredo, A.C.M. and Coelho, C.M. 2015: Satisfaction of adult users with oral health care in the family health strategy. [Satisfação dos usuários adultos com a atenção em saúde bucal na estratégia de saúde da família]. Cadernos Saúde Coletiva 23, 163-71. 
Gonçalves, C.A., Vazquez, F.L., Ambrosano, G.M.B., Mialhe, F.L., Pereira, A.C., Sarracini, K.L.M., Guerra, L.M. and Cortellazzi, K.L. 2015: Strategies for coping with absenteeism in dental consultations in the Family Health Units of a large municipality: an action research [Estratégias para o enfrentamento do absenteísmo em consultas odontológicas nas Unidades de Saúde da Família de um município de grande porte: uma pesquisa-ação]. Revista Ciência \& Saúde Coletiva 20.2, 332-36.

Khan, K., Ruby, B., Goldblatt, R.S., Schensul, J.J. and Reisine, S. 2014: A pilot study to assess oral health literacy by comparing a word recognition and comprehension tool. BMC Oral Health 14, 135.

Macek, M.D., Atchison, K.A., Chen, H., Wells, W., Haynes, D., Parker, R.M. and Azzo, S. 2017: Oral health conceptual knowledge and its relationships with oral health outcomes: findings from a multi-site health literacy study. Community Dentistry and Oral Epidemiology 45, 1-7.

Martins, L.F.V., Meneghim, M.C., Martins, L.C. and Pereira, A.C. 2014: Quality evaluation in public health services based on the perception of users and professionals [Avaliação da qualidade nos serviços públicos de saúde com base na percepção dos usuários e dos profissionais]. RFO 19, 151-58.

Mendes, E.V. 2001: The great dilemmas of SUS [Os grandes dilemas do SUS]: Tomo I. 1ed. Casa da qualidade Editora, Salvador BA, 144pp.

Mendes, E.V. 2002. Primary helath care in SUS [A Atenção Primária à Saúde no SUS]. Fortaleza: Editora Escola de Saúde Pública do Ceara.

Moimaz, S.A.S., Marques, J.A.M., Saliba, O., Garbin, C.A.S., Zina, L.G. and Saliba, N.A. 2010: Satisfaction and perception of the SUS user about the public health service [Satisfação e percepção do usuário do SUS sobre o serviço público de saúde]. Physis: Revista de Saúde Coletiva 20, 1419-440.

Nicoli, M.A., Martino, A., Marta, B.L., Baptista, G.C., Guimaraes, C.F., Sintoni, F. and Ferla, A.A. 2016: It is not only a problem of user satisfaction: considerations about the participation of users in the evaluation of basic care. [Não é só um problema de satisfação dos usuários: considerações sobre a participação dos usuários na avaliação da atenção básica]. Saúde em Redes 2, 23-42.

Protasio, A.P.L., Silva, P.B., Lima, E.C.L., Gomes, L.B., Machado, L.S. and Valença, A.M.G. 2014: Evaluation of the system of reference and counter-referral of the state of Paraíba according to the professionals of Primary Care in the context of the 1st cycle of External Evaluation of PMAQ-AB. [Avaliação do sistema de referência e contrarreferência do estado da Paraíba segundo os profissionais da Atenção Básica no contexto do $1^{\circ}$ ciclo de Avaliação Externa do PMAQ-AB]. Saúde debate 38, 209-20.

Rocha, R.A.C.P. and Goes, P.S.A. 2008: Comparison of access to oral health services in areas covered and not covered by the Family Health Strategy in Campina Grande, Paraíba, Brazil [Comparação do acesso aos serviços de saúde bucal em áreas cobertas e não cobertas pela Estratégia Saúde da Família em Campina Grande, Paraíba, Brazil]. Cad Saúde Pública 24, 2871-880.

Schneider, F.P. and Botazzo, C. 2015: Technological organization in oral health in SUS: an archeology of national policy for oral health. Saúde e Sociedade 24, 273-84.

Silva, Z.P., Ribeiro, M.C.S.A., Barata, R.B. and Almeida, M.F. 2011: Sociodemographic profile and pattern of use of the health services of the Unified Health System (SUS). [Perfil sociodemográfico e padrão de utilização dos serviços de saúde do Sistema Único de Saúde (SUS)]. Ciência \& Saúde Coletiva $16,3807-816$.

Sobrinho, J.E.L., Martelli, P.J.L., Albuquerque, M.S.V., Lyra, T.M. and Farias, S.F. 2015: Access and quality: evaluation of Oral Health Teams participating PMAQ-AB 2012 in Pernambuco. Saúde em Debate 39, 136-46.

Starfield, B. 2002. Primary care: concept, evaluation and policy. Oxford: Oxford University Press.

Van Stralen, C.K., Belisário, S.A., Van Stralen, T.B.S., Lima, A.M.D., Massote, A.W. and Oliveira, C.L. 2008: Perception of users and health professionals about basic care: comparison between units with and without family health in the Center-West Region of Brazil [Percepção dos usuários e profissionais de saúde sobre atenção básica: comparação entre unidades com e sem saúde da família na Região Centro-Oeste do Brazil]. Cad Saude Publica 24, s1.

Whitelaw, S., Thirlwall, C., Morrison, A., Osborne, J., Tattum, L. and Walker, S. 2017: Developing and implementing a social prescribing initiative in primary care: insights into the possibility of normalisation and sustainability from a UK case study. Primary Health Care Research \& Development 18, 112-21. 